\title{
First Nations Experience of the 2013 Alberta Floods: Media Representations and First Hand Experiences
}

\author{
Thurston WE* and Schill KA \\ University of Calgary Cumming School of Medicine, Calgary, Alberta, Canada
}

\begin{abstract}
Background: In June 2013, a severe flood affected Southern Alberta. According to the Government of Alberta, the "scale and impact of the flooding [were] unprecedented in Alberta", causing significant damage to homes and infrastructure. Many of the affected residents were from the First Nations reservations of Siksika and Stoney, outside the Calgary city limits.
\end{abstract}

Objective: To explore how non-Aboriginal Canadians frame First Nations' experience of the floods in print media, and how individuals involved in flood relief coordination respond to these frames.

Methods: We combined the results of a media analysis of mainstream print media with semi-structured interviews to achieve our objective. Articles from four Canadian newspapers and one international newspaper were included in the media analysis. Three individuals involved in flood relief coordination on reserve were interviewed.

Results: Four frames emerged from the media analysis; the "sympathetic", "unprecedented support", "unappreciative (or whining)", and "property damage or loss" frames. The interview data revealed a perception of bias in print media and that the media coverage of First Nations' experience of the floods was inadequate and inequitable. Participants felt the bias in the media reflected larger social issues surrounding First Nations in Canada. Participants perceived the media as a tool and as a "double-edged sword".

Discussion: We found evidence of what has been characterized as passive racism in the media. We also found evidence of a dichotomy between First Nation and non-First Nation communities, reflecting a larger social divide. The interview data confirm that.

Keywords: First nations; Print media; Natural disasters; Alberta floods; Media analysis; Media framing

\section{Background and Rationale}

\section{Alberta floods}

In June 2013, a severe flood affected a $55,000 \mathrm{~km}^{2}$ area in southern Alberta, Canada. In addition to the provincial state of emergency (unique in Alberta's history), 29 local states of emergency were declared across the province. According to the Government of Alberta, the "scale and impact of the flooding [were] unprecedented in Alberta", causing significant damage to homes and infrastructure across the province [1]. Initial estimates place the number of evacuated Albertans at over 100,000 , with many of these still unable to return home because of the damages as of March 2014. Many of these residents were from the First Nations reservations of Siksika and Stoney, outside the Calgary city limits.

\section{First nations history}

In 1877 , Treaty 7 was signed by the Government of Canada and the chiefs of several First Nations groups. By signing the treaty, the First Nations ceded their rights, titles and privileges to over 35,000 square miles of land, in what is now Southern Alberta, to the government of Canada, and Her Majesty the Queen of England. As partial compensation for ceding their rights to the territory, a reservation system was put into place. The federal government of Canada was granted responsibility for First Nations lands, education and medical care through this act [2]. Today, the implementation of treaty rights are controversial, and a source of tension between First Nations groups and the Canadian federal government.

In 1991, the Canadian government formed the Royal Commission on Aboriginal Peoples (RCAP) to help address problems faced by
Aboriginal communities. In 1997, the commission released a summary on its findings. Among the findings was the conclusion that past colonialist policies contributed to the devaluation and erosion of Aboriginal culture and identity. Further, the commission found that Canada's colonial history continued to perpetuate negative and harmful perceptions of Aboriginal Canadians, contributing to inequitable treatment in Canadian society [3]. The commission also found that "social programs continue to fail Aboriginal people on a massive scale". In accordance with these findings, the commission recommended that social policy (including those that affect the media) should reflect the unique culture and history of Aboriginal Canadians.

In 2008, the Truth and Reconciliation Commission of Canada (TRCC) was established to "reveal to Canadians the complex truth about...residential schools... [and to] guide and inspire a process of truth and healing...to renew [Aboriginal and non-Aboriginal] relationships on a basis of inclusion, mutual understanding, and respect" [4]. The TRCC heard from survivors how they lost their individual and cultural identities during their time in residential schools. Many of these survivors felt they had not only lost their ability

*Corresponding author: Thurston WE, Department Community Health Sciences Cumming School of Medicine, Faculty of Veterinary Medicine University of Calgary Cumming School of Medicine, Calgary, Alberta, Canada, Tel: 4032206940; E-mail: thurston@ucalgary.ca

Received May 25, 2014; Accepted June 18, 2015; Published June 28, 2015

Citation: Thurston WE, Schill KA (2015) First Nations Experience of the 2013 Alberta Floods: Media Representations and First Hand Experiences. J Mass Communicat Journalism 5: 261. doi:10.4172/2165-7912.1000261

Copyright: (c) 2015 Thurston WE, et al. This is an open-access article distributed under the terms of the Creative Commons Attribution License, which permits unrestricted use, distribution, and reproduction in any medium, provided the original author and source are credited. 
to speak in their native tongues but also felt that they, as a group, had lost their "voice", or the ability to have their experiences heard and legitimized by non-Aboriginal Canadians. Once Canada abolished the residential school system, former students felt that they and their communities were abandoned and left to recover this voice without the support of the government or fellow Canadians. In order to achieve the goal of renewing the relationship between Aboriginal and NonAboriginal Canadians, the TRCC concluded that greater value ought to be placed on Aboriginal knowledge and experience. Part of this process of renewal depends on how social institutions, such as the media, invest in the restoration of Aboriginal culture and respect for Aboriginal peoples [4].

\section{Media framing}

The power of text, and how it guides reader understanding of social issues, can be explored using analysis of framing [5]. In framing analysis multiple perspectives are recognized for any one issue, and one or more of these perspectives are used to orient how "people notice ... understand and remember a problem, as well as how they evaluate and choose to act upon it" [5,6]. Frames guide this cognitive process of information processing by making particular aspects of an issue more salient, and thereby "becom[ing] important in influencing individuals' judgments" [7]. By influencing how individuals perceive a problem, the media plays an important role in shaping public and political opinion about social issues, and also reflects broadly accepted frames $[5,6]$. The media often uses frames that are accepted (and often expected) by the public to frame social issues, serving to reinforce public opinion by using the expected frames. Therefore, media analysis can be a useful tool in understanding how social problems are understood and addressed by the population and changes in how the media frames issues may result in changes in social ideology $[6,8]$.

While the media frames issues to make particular aspects more salient, it also serves to minimize or restrict alternate aspects [7]. It does so by "call[ing] attention to particular aspects of the reality described... [while] simultaneously direct[ing] attention away from", or failing to present, alternate perspectives [5]. By examining which perspectives are used and which are restricted, framing can be an important tool in examining power imbalances and social inequities, and how such relationships are normalized.

\section{Rationale}

Analysis of mainstream print media provides us with the means to gain insight into how non-Aboriginal Canadians understand and address Aboriginal issues. By combining the results of the media analysis with interviews of individuals involved in flood relief coordination, we explored how these frames were understood by flood relief coordinators in First Nations communities during the 2013 floods.

We conducted a literature search of the Academic Search Complete database, using the key words: (First Nation ${ }^{\star}$ OR Aboriginal ${ }^{\star}$ OR Native Indian ${ }^{\star}$ OR American Indian ${ }^{\star}$ OR Inuit OR Metis) AND (Disaster ${ }^{\star}$ OR Flood $^{\star}$ OR Natural Disaster ${ }^{\star}$ ) AND (Experience ${ }^{\star}$ ). The search resulted in only one academic article on indigenous experience of natural disasters. This shows that very little attention has been paid by academia to Aboriginal experience of natural disasters, though we know this is not the first time they have been the victims of such events. Studying how the media framed the event in Alberta works towards developing an understanding of the experiences of a population that we have already described as suffering social discrimination and neglect.

\section{Research Question and Objectives}

\section{Research question}

How has the mainstream print media framed the experience of First Nations communities during the 2013 Alberta floods, and how did individuals involved in flood relief coordination respond to the frames found?

\section{Objectives}

The objectives of this research project were to:

1. Assess the number of media articles about First Nations experience during and after the flood event (June 20, 2013-November 20, 2013);

2. Analyze the articles to determine how the media framed the experience of First Nation communities during and after the flood event; and,

3. Conduct interviews with First Nations flood relief personnel to explore their reaction to the media analysis results.

\section{Methods}

Research design: This study was of a qualitative design.

\section{Samples}

Media: The electronic database ProQuest was used to search for articles pertaining to the floods, limiting the database search to four Canadian (Calgary Herald, Edmonton Journal, The Globe and Mail, and The National Post) and one international (New York Times) newspaper. The search was also limited to a five month time frame (20 June, 2013-20 November, 2013). To find articles relevant to First Nations experience during the 2013 Alberta floods, the following search terms were used: Flood ${ }^{\star}$ AND (Tsuu Tina ${ }^{\star}$ OR Blackfoot OR Blackfeet OR Sarcee OR Bearspaw OR Chiniki OR Goodstoney OR Wesley OR Stoney Nakoda OR Native* OR Morley OR First Nation ${ }^{\star}$ OR Aboriginal $^{\star}$ OR Siksika OR Reservation ${ }^{\star}$ ).

The initial search resulted in 860 articles. Next, the researchers assessed the titles and abstracts of the articles for relevance, including articles specifically about First Nation experience of the 2013 Alberta floods. Applying the inclusion criteria resulted in 36 articles. After full text review, articles that mentioned First Nations communities in passing, rather than focusing on the Nations affected, were discarded. 23 articles remained in the final media analysis.

Interview: We successfully recruited 3 interview participants between January and March 2014, for participation in this study, using a combination of convenience and snowball sampling to recruit participants. We approached key informants who were involved in flood relief coordination in First Nation communities, however, First Nation identity was not included in the eligibility criteria for the interview participants.

Individual, in-person interviews took place at various locations and times at the convenience of the participants. Individuals who agreed to participate in the study received copies of the media analysis report to read prior to the interview. Interviews lasted between twenty minutes and one hour, using a semi-structured format to allow for in-depth understanding of the issue [9]. Interviews began with the interviewer asking the participant to explain their role in flood relief coordination and their reaction to the media analysis report. The questions then progressed to focus on the media coverage of First Nations communities 
Citation: Thurston WE, Schill KA (2015) First Nations Experience of the 2013 Alberta Floods: Media Representations and First Hand Experiences. J Mass Communicat Journalism 5: 261. doi:10.4172/2165-7912.1000261

Page 3 of 7

and the impact of media on flood relief coordination in the community. Participants were encouraged to talk about other issues they thought relevant to the topic. The interviewer digitally recorded and transcribed the interviews in full using the established methods of Poland, listening to the recording multiple times to check for transcription accuracy [10].

\section{Analysis}

Media: The articles relating to First Nations experience during the floods were collected as PDF documents, and loaded into NVivo10. An inductive approach to analysis was used because of the little existing research on the topic from which to draw a coding template [11]. Data was initially assessed using a system of open coding. The resulting codes were then grouped together to form more general categories. To complete the content analysis, themes derives from these categories were used to generate a report.

Interview: Following the thematic analysis methodology of Green, the interview data was systematically analysed [12]. First, the researchers immersed themselves in the data by reading, and rereading, the interview transcripts. Next, codes (i.e., descriptive labels) were applied to the transcripts to begin the process of organizing and classifying the data. Third, the codes were linked to form categories. Although the participants had different experiences and backgrounds, this process of data analysis allowed us to look for similarities and differences between the interviews. It was from these similarities and differences the categories emerged [13]. Finally, we drew themes from the categories. This process involved interpreting and explaining the categories in the context of existing literature and relevant theoretical concepts [12]. Quotations that best exemplified the themes are included in the results.

\section{Results}

\section{Media analysis}

Four frames were drawn from the newspaper articles collected for the media analysis; we have called these the "sympathetic frame", the "unprecedented support frame", the "unappreciative or whining frame", and the "property damage or loss" frame. Sympathetic Frame. Several articles took a very sympathetic approach to the situation of flooded First Nations; for instance, Colettede and Stark's article was titled "Many First Nations in 'crisis mode'; 1,000 people evacuated from Siksika alone" and the content reflected the toll of the flood on First Nations communities: ...it's very stressful. The worst I've ever seen, it's devastating...the combination of a spread-out community, such as a reserve and people living in poverty intensified [the effect of the flood] even more [14-20].

Unprecedented Support Frame: The term unprecedented was explicitly used to frame the level of support provided by the federal and provincial governments in several articles (Table 1) [21-23]. Where the term was not used explicitly, it was implied in how information was presented, using phrases such as: Redford...promised that the provincial government would support Siksika's cleanup and recovery efforts... [and] Campbell said that the federal government has also promised support...the province "isn't waiting" for them [24-27].

Unappreciative or Whining several articles framed the First Nation response as expecting too much, or not appreciating what was provided (Table 1) [21,24,28-31]. The articles juxtaposed images of what First Nations communities were receiving, with feeling of neglect or dissatisfaction among community members:

\begin{tabular}{|l|c|}
\hline Frame & Number of Articles \\
\hline Sympathetic & 7 \\
\hline Unprecedented Support & 7 \\
\hline Explicit & 3 \\
\hline Implicit & 4 \\
\hline Unappreciative or Whining & 7 \\
\hline Articles & 6 \\
\hline Letter to the Editor & 1 \\
\hline Property Damage and Loss & 22 \\
\hline
\end{tabular}

Table 1: Number of Articles by Frame.

...trailers with enough room to accommodate 100 people... were opened on Tuesday...The units are fully furnished, contain washrooms, televisions and beds as well as food, housekeeping and internet access... And while flood victims said they're happy to have shelter, some are balking at the strict rules the company has imposed... "They're absolutely small, there's no privacy and we have to abide by the rules" [30].

Interestingly, one Calgary Herald reader made reference to this frame in a letter to the editor. In "Whining should stop", writes: Why is it then, that, when given free housing in trailers... the Siksika Nation can do nothing but complain?...I am at a loss to understand the extent of this ingratitude...somehow, it appears, they are expecting a lot more. And, they seem to be expecting everyone else to do it for them [32].

Material Possessions: A majority of the articles $(n=22)$ framed property damage and loss as the most important outcome of the floods (Table 1). While framing the issue in terms of property damage and loss, two articles alluded to the resulting stress and emotional toll of the loss, and one article framed the loss of physical objects as the "washing away [of] irreplaceable family treasures passed down through generations" $[14,15,33]$. Only one article did not explicitly mention property damage or loss, exclusively covering the donation of GlobalFest tickets to "uplift the spirits of the people [26]."

\section{Interview analysis}

Bias in the media: One of the main themes that came out of the interview data was the notion of a bias in print media. P2: If you look at, I think it was George Canyon, I think it was 2 or 3 weeks after the flood, ran a fundraiser in Strathmore. And that got a lot of coverage. And they raised $\$ 50,000$. You know, 4 days after the flood we had an event and we raised $\$ 80,000$, no one even paid attention to that. So, it's not just my opinion that there's a bias in the coverage.

This theme came out through different sentiments - the participant discussed the feeling that the media coverage of the First Nation experience overall was inadequate, and that the coverage was also inequitable.

Inadequate coverage: There was consensus among the participants that First Nations communities were covered inadequately in the print media. For example, participant two felt that the coverage of flood relief fundraisers organized by First Nations was inadequate, and affected crowd turn out of as result: P2: It was really nice out. And we could have held 20,000 people in the venue we were using [...] and probably the biggest crowd we got was Saturday afternoon, of I don't know, 5,000 people maybe[...] we didn't get the kind of coverage that we hoped that it would. Participant three was concerned with the coverage of individuals affected by the flood in First Nation communities: KS: Did you feel [...] that the media was being fair in the amount of coverage [on First Nations affected by the floods]? P3: No. No, not at 
all. Not at all. As far as, looking at it from a people perspective, who was impacted, how they were impacted, and how they were doing, that wasn't adequately addressed.

The participants also agreed that the media coverage during the flooding was typical of the coverage First Nations receive on a regular bases. Participant one stated simply that they were "not surprised", while participant three tied the regularity of inadequate media coverage of First Nations issues to a bias in the media:

P3: I think what you find in the coverage that happened during the flood is pretty much what you'd find almost any given day. Further, participant three indicated that, while "First Nations" were mentioned in the media coverage during the floods, the coverage tended to treat the communities as homogenous. This resulted in inadequate coverage for the individual communities, and the unique problems they faced during and after the flood: P3: Did I hear about [our community] too much? I'll be honest with you, not a lot. I mean they kind of just glumped "The First Nations" together, while there's more, more than just that, you know (chuckle).

Inequitable coverage: The participants indicated that not only was the coverage inadequate, but expressly overlooked the contribution of First Nations in recovery efforts. For example: KS: We noticed other fundraisers were in the newspaper [...] do you have any idea why those received attention and yours didn't?

P2: Because we were running it, it was totally done by us. We had, just about all Native acts from really big name First Nation or Indian performers from across Canada. Um, comedians, uh, singers [...] we had so many entertainers volunteer to come in on their own nickel and perform we had to start saying no to people.

It was also noted by participants that the media tended to focus on First Nation communities primarily when non-First Nation people were involved, indicating inequity in the coverage. For example, participant one noted that the media only seemed to visit affected First Nation communities when politicians were visiting:

P1: Responses and reactions to this could be more, I think, publicly stated if the media did go to those communities to try and find out, and not just go out when the politicians go to the communities, cause when the politicians went, then the media, when, other than that, they didn't go out. Participant two also noted that, while First Nation and non-First Nation communities faced similar challenges, the media used different frames when covering each: P2: You would see the same kind of comments made by [First Nations residents] about how disorganized the help was, and how cramped the quarters were, and then you switched to High River, and you hear people saying exactly the same thing. And yet, the editorial comment, whether it was in the paper or in the print, or the electronic [media], played up how ungrateful First Nations people were, versus how badly off the people in High River were, and the government needs to fix these problems.

Media coverage is a symptom of larger social issues: The participants indicated that the inadequate and inequitable print media coverage First Nation communities received during and after the floods was indicative of larger social issues surrounding First Nations in Canada. For example: P2: The kind of coverage you saw, the lack of coverage you saw, is really symptomatic of, I think, a larger societal issue, and the place that most people view First Nations in the world. You know, if the world's out here, First Nations are somewhere way back here.

Participant one indicated that the media plays a role in perpetuating the dysfunction in, and surrounding, First Nation communities in Alberta: KS: Was this media coverage any different from media coverage of other events in recent memory? P1: No, I guess as far as to prevent or, further perpetuating the dysfunction of First Nations communities, it's sort of been, it's pretty consistent [...] it's like an "us" and "them" mentality in this geographic area. Aboriginal people are, typically, marginalized in mainstream systems.

It was noted by participant two that print media is an institution that "caters to its audience, just like any other media does", further suggesting that the demographic print media caters to existing and accepted frames among non-Aboriginal people and more negative ideas of First Nation members: P2: So the demographic that reads the papers is probably that older generation, and the people who had, you know, their stereotypes, the 'drunk Indian', the person who can't work, or hold a job, and is always looking for a handout.

Media as a tool: There was some disagreement between interviews regarding the role of media coverage, and the level of engagement with media in First Nation communities. In one interview, there was the perception that there was minimal contact between First Nations communities and media personnel resulting from shortcomings on the side of the community and the media: P1: Well, the most obvious factor that I saw in this was that the media didn't necessarily go to the communities to find out how they were impacted. They relied on word of mouth. On the side of the community, there weren't press releases provided to the media around what it was that had happened, and how they were prepared to, respond to the event. Um, they don't have educated communications people in First Nations communities, um, to get the word out, so it's, it's mostly by word of mouth [...].

Participants two and three indicated that this was not the case; rather, both First Nation communities did reach out to the media, with mixed results: P3: The comments about, the media being a little slow to react? Actually it was myself that [said] [...] look, we've gotta call the media, because [...] everything focuses on Calgary and High River, a lot of people are just not realizing that there are communities downstream. [...]Let them know, so that the people can understand what's going on. And the second that word got out, I mean, we got the attention that we require [...] So if I'd have kept quiet, in fact, nothing could have happened out here.

However, participant two had a slightly different experience: P2: And during the flood, we provided [print media] the same information that we did with the electronic media, and got very little response. We got coverage from all the major radio stations. I probably did 25 or 30 interviews with different radio stations as far away as, I did some in Toronto and New York [...] the story got picked up and ran all over the place, but not in our print media. Participant one also mentioned that increased contact might result in more favorable media coverage for First Nations communities: KS: Right, ok. Ok. Um, did you feel that the stories or the type of coverage were fair or accurate?

P1: Given the limited contact they had with the communities, it was, proportionally fair. Had they had more, more engagement, it would have been more adequate, but I think it was somewhat inadequate [...] if there was outreach to the media or the general public through a communications person, it probably would be much more favorable. This view was not supported by participant two, who felt that it is to the advantage of some communities to stay out of the media: P2: And [the media is] a tool that helps you reach your objectives, and if you can get public opinion on your side, on a certain particular situation, then it forces the government to pay attention, and that's quite frankly how 
I've always viewed the media. It's a tool. You learn how it works, and you understand what motivates them, then you use it to your advantage. And I've done that for a long time. And here it's to our advantage not to be in the media [...] In other areas where they don't have the kind of opportunities we do, it's to their advantage to get as much attention as they can [...] if we feel we need to get a message out, we have avenues to do that. But on a day to day basis, we would prefer not to.

Media as a double edged sword: The theme of media coverage being a "double edged sword" also emerged from the data. This theme indicates that, while there are benefits to using the media as a tool or form of recourse, it can be detrimental at the same time. P3: I know that when the word got out, and we started to, let's say, ask them for donations and stuff, because again, I use the media to my advantage for that particular point, we got the response.

KS: So, what [was the] negative impact that happened as a result of that, kind of, confusion around what the media was reporting? P3: Well, just getting a stockpile of stuff that we had absolutely no use for [...] not getting it clear on the message out, when we were asking for clothing, you know, nice clean, washed stuff (laughter). Not used, dirty stuff. So, stuff like that. I mean, there's, unfortunately there's a lot of stuff that we had no use for. Another participant noted that the media generates controversy, an undesired consequence of media coverage in First Nations communities: P2: They get a little frustrated with us, because on a slow news day they look to us to generate something for them. But they always want controversy, and that's not what we're about. We just want to go along and do our business [...] The negative spin was part of what we tried to avoid, because controversy is what sells, and we don't want to get into controversy, and we don't want our people exposed to that.

Social media: Two of three participants noted that the use of social media by community leadership was rising, in an effort to control media output, and how community issues are presented and discussed: P3: Well, just about anyone can put their own comments on Facebook, so we had to get control of that because people were saying different things, and of course everyone is reading this stuff [...]. So, recognizing that, we had to get permission from the chief and council, can we create our own official Facebook page. And, of course, once that got done we kind of got some control over that. But, I mean, it was something new we learned. That, you know, that was something I've been meaning to do in terms of controlling what's being said, and how it's being presented.

The notion of using social media to reach the target audience also emerged from the data. One participant alluded to the unique population pyramid in First Nations communities, and how social media is useful in reaching the appropriate demographic: P2: I think that the print media, except with the older demographic, is less and less important, and will probably be less and less important as we go forward. So, when we want to reach out to people, like our population is, $66 \%$ of our population is under the age of 30 , so from the communications perspective, we follow the media, and we follow the social media, and we try to understand how to use that to get our messages out.

\section{Discussion}

\section{Strengths and limitations}

The strength of this study lay in the study design, which used two convergent methods to investigate the same topic. Having key informants was an advantage because while we were able to interview only a small number of participants, they provided us with a wealth of informed reflection on media coverage of First Nations during and after the flood from an insider's perspective. As we were able to answer our research question with a small number of key informants, it was not necessary to pursue additional participants who were still dealing with the impact of the flood.

We were unable to acquire back copies of an Albertan First Nation publication in time to include in our analysis. This limits the conclusions we can draw, insofar as we are unable to ascertain whether the frames found are used exclusively in the mainstream print media, however, that was not our research question and could be addressed in another project. It was mentioned in one interview that one shortcoming of media coverage is the tendency to "glump" First Nation communities together (i.e., to ignore distinctions between communities). This also creates a limitation in this project as we did not make the distinction between communities in our analysis. While there are strengths to not making the distinction between communities, particularly when there is such a dearth of articles on the subject, future research may aim to differentiate between the communities affected to compare and contrast how communities use and understand the role of media in emergency response.

\section{Key Findings}

\section{Racism in the media}

Previous literature has found that overt racism targeting Aboriginal Canadians largely disappeared from mainstream print media in the mid- to late- $19^{\text {th }}$ century, and has been replaced by a more "passive racism", characterized by ethnocentrism [34]. Ethnocentrism is defined by Harding as a targeting non-Aboriginal audiences and excluding the Aboriginal voice from media discourse, instead "falling back on old stereotypes, such as Aboriginal-as-victim" [34]. He also found that news articles tend to frame Aboriginal issues in binary terms (e.g., "us versus them"). We found evidence of this passive racism in our analysis of both the media and interviews. In the media analysis, the Whining/ Unappreciative frame demonstrates subtle racism by portraying First Nation community members as unjustifiably ungrateful for what they have received from the Canadian government and mainstream society. To use Harding's turn of phrase, by using the Whining/ Ungrateful frame, the media falls back onto old stereotypes of First Nation members as always-looking-for-a-handout and unwilling-tohelp-themselves. This frame plays on the the assumption that if one works hard and keeps their nose clean (i.e., behaves in the 'appropriate' manner), they can be successful. Like Irlbacker-Fox's commentary on Canadian Policy, the use of this framing in newspaper articles indicates a lack of historical and social context, "focus[ing] on 'present suffering' as though that suffering were unrelated to injustice and instead primarily the result of poor lifestyle choices and the non-modern nature of indigeneity [35].”

Data from the interviews likewise supported Harding's claim that racism in the media has transitioned to a more subtle form. Our results demonstrate that participants felt that the media coverage of the floods was inadequate and inequitable, largely removing Aboriginal voice from the discourse surrounding the effects of the floods [34]. Participants also referred to the dichotomy Harding discusses, both explicitly and implicitly. This dichotomy reflects and reinforces a larger social divide between First Nation and non-First Nation Canadians. While not explicit in today's print media, this division occurs between the superior (non-First Nation communities) and inferior (First Nation communities) Canadians, and is used to justify oppressive and inequitable Canadian policy. 
Negative and stereotypical representations of First Nation communities in the mainstream print media, therefore, may contribute to health and social inequities in Canada through the promotion of racism. It is imperative that all Canadians, not only First Nations, take the impetus upon themselves to develop cultural competence and challenge harmful and negative frames in the media to address the problem of racism against Aboriginal Canadians [36]. Future research may wish to explore in more detail the relationship between media representations, racism and health in Canadian populations, to understand both the mechanisms involved and factors that contribute to resiliency in First Nation communities.

\section{Contemporary first nation approaches to media engagement}

Harding describes "modern" Aboriginal organizations as having "media relation branches that systematically attempt to influence reporting on Aboriginal issues and counteract 'bias' in the press" [34]. Our findings do not support this argument. Rather, the interview data indicated that contemporary First Nation media teams regard the media both as an adversary and as a tool. Some communities perceived it to be to their advantage to be in the mainstream media, while for other communities, participants described the official media policy as actively avoiding media coverage. In one interview, the participant not only described the community's policy of avoiding the media, but also added that it was not a community priority to change the negative perceptions of the community on a larger scale.

The difference in community approaches to media engagement indicates that First Nation communities take a more nuanced approach to media relations, and harkens back to the "media as a double-edged sword" theme that emerged from the data. Because mainstream print media tends to sensationalize First Nations issues, causing controversy at the same time as it brings issues to light, there is careful consideration by leadership before the media is engaged to ensure the pros of media coverage outweigh the cons. For example, when using the media to criticize government response to events like natural disasters, vulnerable communities may wish to avoid attacking the institutions (e.g., the federal government) on which they rely for funding or social support.

Our results also indicate that, while structural and institutional racism is a serious problem in Canadian media that Canadian media ought to address, the assumption that the priority of First Nations is favourable or increased mainstream media coverage may be ethnocentric in and of itself. Rather, participants described media relations as internal in focus, with the primary aim to reach community members, rather than to change external perceptions of their communities.

\section{Social media}

McMahon describes "digital self-determination" as a process by which Aboriginal communities use and develop technologies to meet their needs of self-determination, and providing community members a means of emerging as agents and political actors in an otherwise oppressive context [37]. Our findings support this argument. As First Nation communities begin to focus their efforts less and less on the print media, future research should reflect this shift and may instead aim to understand how social media acts as a medium for social change in First Nation communities, allowing community members and leadership the opportunity to emerge as independent agents in Canadian society.

\section{"Glumping" first nations together}

One participant noted the tendency of the mainstream media to "glump" First Nation communities together. By grouping them together in the media coverage of the flood, the media may have hidden the fact that the floods affected the communities differently, and the communities had different resources and emergency plans in place. This may have detrimental effects for how aid was dispersed (including donations) in the aftermath of natural disasters.

\section{Conclusion}

This study adds to scant literature on the experience of First Nation communities during and after natural disasters, and contributes to existing literature on representations of First Nation communities in the media. Further, this study reveals examples of how social institutions like the media continue to play a role in shaping the everyday lives, and therefore health, of Aboriginal peoples. Of particular note are the findings that the mainstream print media inadequately represented First Nation communities during and immediately following the 2013 Alberta floods. This finding supports the existing literature. Our findings refuted the notion that First Nation communities desire, or ought to desire, increased attention in the mainstream print media. Rather, our results indicate that First Nation communities use the media as a tool when it is advantageous to do so, and avoid coverage when it may be harmful, recognizing they have little control over media frames that perpetuate racism. We also found that, increasingly, First Nation communities are using social media to connect with their members and the public about First Nation issues. The role of communication, type of media used, and impact on this population's health warrants further attention.

\section{References}

1. Government of Alberta Flood Recovery Task Force (2013) Southern Alberta 2013 Floods The Provincial Recovery Framework.

2. Treaty No.7 (1877) Her Majesty the Queen-Blackfeet and other Indian Tribes.

3. The Institute on Governance (1997) Summary of the Final Report of the Royal Commission on Aboriginal Peoples. Ottawa, ON

4. Truth and Reconciliation Commission of Canada (2008) Truth and Reconciliation Commission of Canada: Interim Report. Winnipeg, Manitoba.

5. Entman RM (1993) Framing: Toward clarification of a fractured paradigm Journal of Communication 43: 51-58.

6. Chong D, Druckman JN (2007) Framing theory. Annual Review of Political Science 10: 103-126.

7. Pan Z, Kosicki GM (1993) Framing analysis: An approach to news discourse Political Communication 10: 55-75.

8. Hubbard JC, DeFleur ML, DeFleur LB (1975) Mass media influences on public conceptions of social problems. Social Problems 23: 22-34.

9. Gill P, Stewart K, Treasure E, Chadwick B (2008) Methods of data collection in qualitative research: interviews and focus groups. British dental journal 204 291-295.

10. Poland BD (1995) Transcription quality as an aspect of rigor in qualitative research. Qualitative Inquiry 1: 290-310.

11. Elo S, Kyngäs $H$ (2008) The qualitative content analysis process. Journal of Advanced Nursing 62: 107-115.

12. Green J, Willis K, Hughes E, Small R, Welch N, et al. (2007) Generating best evidence from qualitative research: the role of data analysis. Australian and New Zealand Journal of Public Health 31: 545-550.

13. Ryan GW, Bernard HR (2003) Techniques to identify themes. Field methods 15: 85-109.

14. Derworiz C, Stark E (2013) First nations hit hard as help arrives slowly; 1,000 residents of siksika forced to leave when bow river crested. Edmonton Journal. 
Citation: Thurston WE, Schill KA (2015) First Nations Experience of the 2013 Alberta Floods: Media Representations and First Hand Experiences. J Mass Communicat Journalism 5: 261. doi:10.4172/2165-7912.1000261

Page 7 of 7

15. Derworiz C, Stark E (2013) First nations communities hammered by flood damage; effect of floodwaters worse for the poor. Calgary Herald.

16. Colettede RR, Stark E (2013) Many first nations in 'crisis mode'; 1,000 people evacuated from siksika alone. Edmonton Journal.

17. Ho C (2013) First nations suffer devastation in flood. Edmonton Journal.

18. Tait C (2013) 'I don't want them to see this'. The Globe and Mail.

19. Fraser D, Stechyson N (2013) Siksika band members trade freedom for shelter. Calgary Herald.

20. Fraser D (2013) No swearing allowed in new home; temporary communities for flooded siksika nation residents come with unwelcome rules. Edmonton Journal.

21. Weismiller B (2013) First nations leaders rally for victims; chiefs ensure 'we're part of the response'. Calgary Herald.

22. Benefit concert for first nations (2013) Calgary Herald.

23. Varcoe C (2013) Alberta has $\$ 80 \mathrm{M}$ for flooded siksika. Calgary Herald.

24. Stark E (2013) Premier, residents tour siksika; redford pledges support to community. Calgary Herald.

25. Stoney nakoda officials say shelter available for victims of flooding (2013) Calgary Herald.

26. Fraser D (2013) High river area flood victims to get free GlobalFest tickets. Calgary Herald.
27. Southwick R(2013) Concert to benefit siksika flood victims. Calgary Herald.

28. Fortney $\vee(2013)$ Aboriginals feel neglected amid the devastation. Calgary Herald.

29. Fraser D (2013) Second round of flood aid reaches stoney nakoda nation Calgary Herald.

30. Gerson J (2013) Evacuees object to stiff rules; siksika first nation; firm dictates clothing, conduct for residents. National Post.

31. Fraser D (2013) 'I have nowhere to go,' says stoney nakoda flood victim. Calgary Herald.

32. Stone D (2013) Whining should stop. Calgary Herald.

33. Zickefoose S (2013) Indian village rallies to save family's tradition; siksika flood victim able to set up teepee. Calgary Herald

34. Harding R (2006) Historical representations of aboriginal people in the Canadian news media. Discourse and Society 17: 205-235.

35. Irlbacher-Fox S (2009) Finding Dahshaa: self-government, social suffering and Aboriginal policy in Canada. Vancouver: UBC Press.

36. Oelke ND, Thurston WE, Arthur N (2013) Intersections between interprofessional practice, cultural competency and primary healthcare. Journal of Interprofessional Care 27: 367-372.

37. McMahon R (2013) Digital self-determination: Aboriginal peoples and the network society in Canada. 